\title{
In vitro propagation of Anchote (Coccinia abyssinica) (Lam.) Cogn.]
}

\author{
Folla Bekele, Balcha Abera* and Mezgebe Getahun \\ Biology Department, College of Natural Sciences, Jimma University, Ethiopia.
}

Accepted 10 May, 2013

\begin{abstract}
Coccinia abyssinica (Lam.) Cogn.] (Cucurbitaceae) is a tuberous neutraceutical plant locally known as Anchote (Oromo language). A micropropagation protocol was developed for $C$. abyssinica. Seeds were planted ex vitro in a pot that contained different soil mix ratios, and two weeks old seedlings were used as a source of explants. Shoot tip and nodal explants were sterilized and cultured on full MS medium variously supplemented with 6-benzylaminopurine (BAP), indole acetic acid (IAA), naphthaleneacetic acid (NAA), and indole-3-butyric acid (IBA) to produce adventitious shoot and rooting. High germination percentage (97\%) was obtained from decoated seeds sown on soil mix ratios of 2:1:1 (sand, loam soil, coffee husk, respectively). Sodium hypochlorite at a concentration of $2.0 \%$ exposure of 5 min gave high percentages of survived nodal $(79.43 \pm 0.6)$ and shoot tip $(74.33 \pm 0.58)$ explants. 6Benzylaminopurine (BAP) $(3.0 \mu \mathrm{M})$ was found to be an optimum concentration for shoot induction, yielding $80 \%$ for nodal and $70 \%$ for shoot tip explants. The combination of BAP $(3.0 \mu \mathrm{M})$ with IAA (0.5 $\mu \mathrm{M})$ was obtained as optimum concentration yielding 13.4 and 11.03 shoots per explants for nodal and shoot tip respectively for shoot multiplication. Half strength MS medium supplemented with IBA (0.5 $\mu \mathrm{M})$ and IAA $(1.5 \mu \mathrm{M})$ yielded more than $90 \%$ rooting with optimum root number and length. For acclimatization, sterilized soil mix of 2:1:1 (top forest soil: coffee husk: sand) was optimized yielding $80 \%$ on transparent polyethylene plastic tube and $82.2 \%$ survived plantlets. This protocol provides a foundation for further studies to generate genetically improved $C$. abyssinica and related cucurbitaceous species.
\end{abstract}

Key words: Plant growth regulators, micropropagation, Sterilants, Explants, Tuber roots, Neutraceutical plant.

\section{INTRODUCTION}

Anchote [Coccinia abyssinica (Lam.) Cogn.] is an annual trailing vine neutraceutical plant belonging to the cucurbitaceae family mainly cultivated for its tuberous fleshy root stock in Ethiopia (Mengesha et al., 2012). Of 30 species of the genus Coccinia, eight were reported to occur in Ethiopia including C. abyssinica (Lam.) Cogn., C. adoensis(Hochst. Ex. A. Rich.) Cogn.), C. grandis (L.) Voigh (Syn. C. indica wight and Arn.), C. megarhiza, C. 
Jeffrey and $C$. schliebenii Harms. The remaining three species have not yet been described (Hora, 1995).

Anchote is traditionally produced on nearly 3000 ha of land in west Wollega Zone where the annual rainfall ranged between 762 to $1016 \mathrm{~mm}$ (Mengesha et al., 2012). According to Fekadu (2011) the raw anchote tuber contains organic (carbohydrate, crude protein, crude fiber) and inorganic substances (calcium, magnesium, iron) as well as low levels of antinutrients (Oxalate, tannin, and cyanide) except phytate, when compared to other tuberous crop plants. The root juice of anchote contains saponin; an active ingredient used to treat gonorrhea, tuberculosis and tumor cancer. A good content of calcium in anchote also helps in fast mending of broken bones (Dawit and Estifanos, 1988; Hora, 1995).

Of the major tuberous vegetables such as sweet potato, Oromo potato, and others cultivated in the area, anchote is widely recognized as cultural, social and economic crop for the local and farming communities in southwest Oromia, Ethiopia with its annual yield of 25,000 tones (Anonymous, 2011). Anchote can be propagated both vegetatively and from seeds. Vegetative propagation is carried out either by planting the whole tuber or by slicing it into two or more pieces, each piece having rootlets and an external covering (Hora, 1995). Since Anchote is a dioecious plant, its pollination and fertilization is limited, thereby, reducing its natural regeneration and population (Mengesha et al., 2012).

Micropropagation is used as a means to improve crop varieties and it has been getting attention and being applied in agricultural research centers. One of the most important application of micropropagation as a tool of biotechnology is its application in the production of disease free plant materials. Moreover, it enables production of large number of plantlets in short period of time as well as maintenance of germplasm under controlled conditions in small spaces and with reduced labor requirement (Hartmann et al., 2002).

There has been progress in tissue culture studies in many Cucurbitaceae members. Studies to promote adventitious shoot from callus of some Cucumis have been unsuccessful or has occurred sporadically and at low frequency (Anugulati, 1988; Rakhi et al., 2010). The regeneration of cucurbits is largely dependent on the nature of explants, the cultivar, the genotype, growth regulator concentrations and physical conditions of culture (Rakhi et al., 2010). However, stimulation of several axillary meristems were able to produce highly increased number of shoots and rooted plantlets within a short period of time (Lee et al., 2003; Tarek et al., 2008).

The present investigation reports micropropagation of
C. abyssinica through nodal and shoot tip explants. The specific objectives of this study were to determine the effect of: 1) soil mix ratios on the germination of seeds; 2) duration of exposure and concentration of sodium hypochlorite $(\mathrm{NaOCl})$ on explants sterilization; 3) BAP and Kinetin on different combination and concentration on initiation of culture; 4) different concentrations of BAP and IAA on multiplication of anchote shoots; 5) different IAA, IBA and NAA concentrations on $1 / 2$ MSmedium on root induction; and 6) to investigate the percentage of plantlets transferred and survived after acclimatization.

\section{MATERIALS AND METHODS}

\section{Plant material}

Fresh matured, yellow-coloured fruits of Anchote variety (var. 29) were obtained from Bishoftu Agricultural Research Center (BARC), dried and stored at room temperature $\left(20^{\circ} \mathrm{C} \pm 2^{\circ} \mathrm{C}\right)$ for further experiment. The experiment was carried out from 20 December, 2011 to 30 September, 2012 at the laboratory of Plant Biotechno-logy (College of Natural Science, Jimma University). Seeds were planted ex vitro in a pot that contained different soil mix ratios: sand, loam soil, coffee husk (2:1:1, 1:1:1, respectively) and grown seedlings were used as a source of explants.

\section{Culture media and explants sterilization}

The amounts of macro- and micro nutrients, organic salts, and vitamins recommended by Murashige and Skoog (1962) were prepared [using double distilled water and agar powder $(0.8 \% \mathrm{w} / \mathrm{v})$, )] autoclaved and kept in a vessel covered with aluminum foil. All the growth regulators used in this experiment were prepared by dissolving the powder in double distilled water at the ratio of $1 \mathrm{mg} / \mathrm{ml}$. The $\mathrm{pH}$ was adjusted using $1 \mathrm{~N} \mathrm{NaOH}$ or $1 \mathrm{~N} \mathrm{HCl}$ followed by addition of distilled water. Finally, growth regulators' stock solu-tions were stored in a refrigerator at a specific temperature for each growth regulator.

Two weeks old healthy and vigorously grown seedlings were selected and used as a source of explants. The shoot tip and nodal $\left(2^{\text {nd }}\right.$ and 3 rd from the top interchangeably) segment explants (1.5 $2.0 \mathrm{~cm}$ ) were excised and washed with tap water and kept in $0.3 \%$ Mancozeb solution for $20 \mathrm{~min}$. This was rinsed with distilled water and consequently surface sterilized in $70 \%$ of ethanol for $30 \mathrm{~s}$ and in different concentration of Sodium hypochlorite $(5.25 \% \mathrm{NaOCl})$ for 5,10 , and 1' min of exposure. This treatment was again rinsed with distilled water three to four times to remove the residual effect of the sterilants. To facilitate the reaction, two drops of $1 \mathrm{mg} / 1 \mathrm{ml}$ of Tween - 20 was added into all the sterilants solutions prior to treatment. Finally, the effect of time exposure was determined for both explants from the culture between two weeks intervals.

\section{Culture establishment}

Both sterilized shoot tip and nodal segment explants were inoculated in test tubes containing full MS (Murashige and Skoog, 1962) medium supplemented with different concentrations of BAP (1.0, 2.0, 3.0 and $5.0 \mu \mathrm{M})$, kinetin $(1.0,2.0$ and $3.0 \mu \mathrm{M})$, sucrose (30 gm 
$\left.1^{-1}\right)$, and agar $\left(8 \mathrm{~g} \mathrm{I}^{-1}\right)$ (Sigma, St Louis MO, USA). Free growth hormone MS medium was used as a control. One explant per test tube was cultured with ten test tubes or five explants per jar with five jars per treatment. The cultured test tubes or jars were incubated in the growth room $\left(25 \pm 2^{\circ} \mathrm{C}\right)$ for three weeks. Then, clean and shoot inducing explants were transferred to fresh media and incubated for another three weeks under light conditions. The same experiment was repeated three times. Data on the percen-tage of initiated shoots per explants were scored after three weeks of the second passages of the culture. The averages of initiated percenttages were received from each replicates for four different BAP concentrations. So there were $2 \times 4 \times 3$ factorial combinations in CRD, to test the four BAP and kinetin concentrations against the two explants, where 0 is used as a control.

\section{Shoot regeneration}

In this experiment, BAP and IAA were used alone and in combinations. To find out the optimum combination for growth regulators and multiple shoot formation, the sprouted shoots were cultured in the medium with growth regulators combinations. All healthy initiated shoots were transferred to free growth hormone medium of half - MS length for four days to reduce latent effects of the previous medium composition. Highly initiated shoots were transferred to shoot multiplication MS fresh media supplemented with BAP (1.0, 2.0, 3.0 and $5.0 \mu \mathrm{M})$ and IAA $(0.5,1.0,1.5 \mu \mathrm{M})$ alone or in combination with each other during fourth week having free PGRs as a control. There were five replicates with five explants per jar for each cultured in each medium. The same treatments were repeated two times to reduce the number of errors. The cultures were maintained at $25 \pm 2^{\circ} \mathrm{C}$ with a $16 \mathrm{~h}$ photoperiod. After four weeks of culture on shoot elongation and multiplication media, the average height of elongated shoots and average number of shoots per explants were recorded. The same procedure was repeated for the same treatment for accuracy of the data. Therefore, the experiment was $2 \times 4 \times 3$ factorial combinations in CRD and treatment with free PGRs used as 0 for control.

\section{Root induction}

The regenerated shoots with minimum length of $2.83 \mathrm{~cm}$ were cultured on half - strength MS media supplemented with $15 \mathrm{~g} / \mathrm{l}$ sucrose and IBA $(0.5,1.0,1.5, \mu \mathrm{M})$ for root induction. Similarly the effect of IAA and NAA were evaluated with the same concentration given for IBA. Free hormone half strength of MS was also used as control. Therefore, the experiment was laid $3 \times 3 \times 3$ factorial combinations in CRD having 0 as a control. There were five replicates with five shoots cultured for each jars. The same procedures for the same experiments were repeated twice for the accuracy of the data. The average percentage of root forming shoots per explant from each jars of the treatments and the average number and length of roots per shoot was scored after three weeks of the culture. To reduce the residual latent effect of the previous experiments of medium compositions, the plantlets were stayed on free PGRs half strength of MS medium for four days before culturing on rooting medium. The cultures were incubated in culture room and provided with a photoperiod of $16 / 8 \mathrm{~h} 25 \pm 2^{\circ} \mathrm{C}$ temperature maintained by automatic photoperiod and temperature controlled device throughout the experiment.

\section{Acclimatization}

After the plantlets were well grown, they were considered to be ready for acclimatization in vivo. Therefore, individual plantlets were removed from the jars and washed carefully under warm but not hot water to facilitate the removal of agar from their roots. Then, they were transferred to sterilized potting mix of loam soil: well decomposed coffee husk: sand, at a respective $\mathrm{v} / \mathrm{v}$ ratio of 2:1:1 in transparent polystyrene plastic tube of $25 \times 16 \times 7 \mathrm{~cm}$ dimension polyethylene plastic tray. They were then kept in light polyethylene tunnel and covered by $70 \%$ shade net above it. The system was designed to give high humidity $(80-90 \%)$ to prevent desiccation for ten days, prior to their transfer to a shade house. In the tunnel, the water was sprayed everyday twice without creating water logging and meant to maintain relative humidity $(\mathrm{RH})$ as high as possible. Starting from the $15^{\text {th }}$ day, the $\mathrm{RH}$ within the system was reduced gradually to $60 \%$ at the end of the month. After the month, the plantlets were transferred to a $70 \%$ shade net, where they were retained for a month. Later they were transferred to a $30 \%$ shade net and maintained there for three weeks. The survival percentages of plantlets were registered in each step.

\section{Statistical analysis}

The experiment was laid in Completely Randomized Design (CRD) with factorial treatment combinations. The experimental design was set to $2 \times 4 \times 3,2 \times 4 \times 3,2 \times 4 \times 3$ and $3 \times 3 \times 3$ factorials for explant sterilization, culture initiation, shoot regeneration and rooting, respectively. Treatment was one factor and explants were another factor. Each shoot tip and nodal culture in a jar was the observational unit. There were five replications per treatment and five explants per jars for each replicate. All explants were cultured on free PGRs medium prior to their use for an experiment so as to avoid any sort of carryover effects from previous culture medium they were retained. Data collected from each experiment was subjected to statistical analyses using the SAS statistical software (version 9.2) and ANOVA was constructed, followed by mean separation using Ryan - Elinot - Gabriel - Welch Multiple Range Test (REGWQ) at $\alpha=5 \%$; was estimated for grouping significant factors on variables from non significant one.

\section{RESULTS}

\section{Seed germination}

The highest percent germination $(97.27 \pm 2.80)$ was recorded from decoated seeds of $C$. abyssinica sawn on a soil mix ratio of 2:1:1 (sand: loam soil: coffee husk, respectively); thiswasrevealedby ANOVAwithP $<0.0001$ (Table 1).

The highest percent contamination was observed from nodal and shoot tip explants treated with low concentration of $\mathrm{NaOCl}(1 \% \mathrm{v} / \mathrm{v})$ and short time exposure (5 and 10 $\mathrm{min}$ ) followed by $1.5 \%$ for $5 \mathrm{~min}$ for both explants but with very low tissue death. However, in the high concentration treatment of $\mathrm{NaOCl}$ and long exposure time, the percentage of contamination was low but explants tissue death was high. Thus, highest percentage $(79 \%)$ of nodal explants were free of contamination when sterilized with 
Table 1. Pot germination capacity of coated and decoated C. abyssinica seeds on different ratio of soil mix after 12 days after culture (DAC).

\begin{tabular}{|c|c|c|}
\hline Type & Basal media & \%of Germ 12DAC (Mean \pm STD) \\
\hline \multirow{2}{*}{ Coated seeds } & $2: 1: 1$ & $24.45 \pm 2.27^{c}$ \\
\hline & $1: 1: 1$ & $15.22 \pm 2.21^{d}$ \\
\hline \multirow{2}{*}{ Decoated seed } & $2: 1: 1$ & $97.27 \pm 2.80^{\mathrm{a}}$ \\
\hline & $1: 1: 1$ & $88.11 \pm 2.82^{b}$ \\
\hline
\end{tabular}

Means within a column followed by the same letters are not statically significant at $p<0.5$ by Ryan - Einot - Gabriel - Welsch Multiple Range Test (REGWQ).
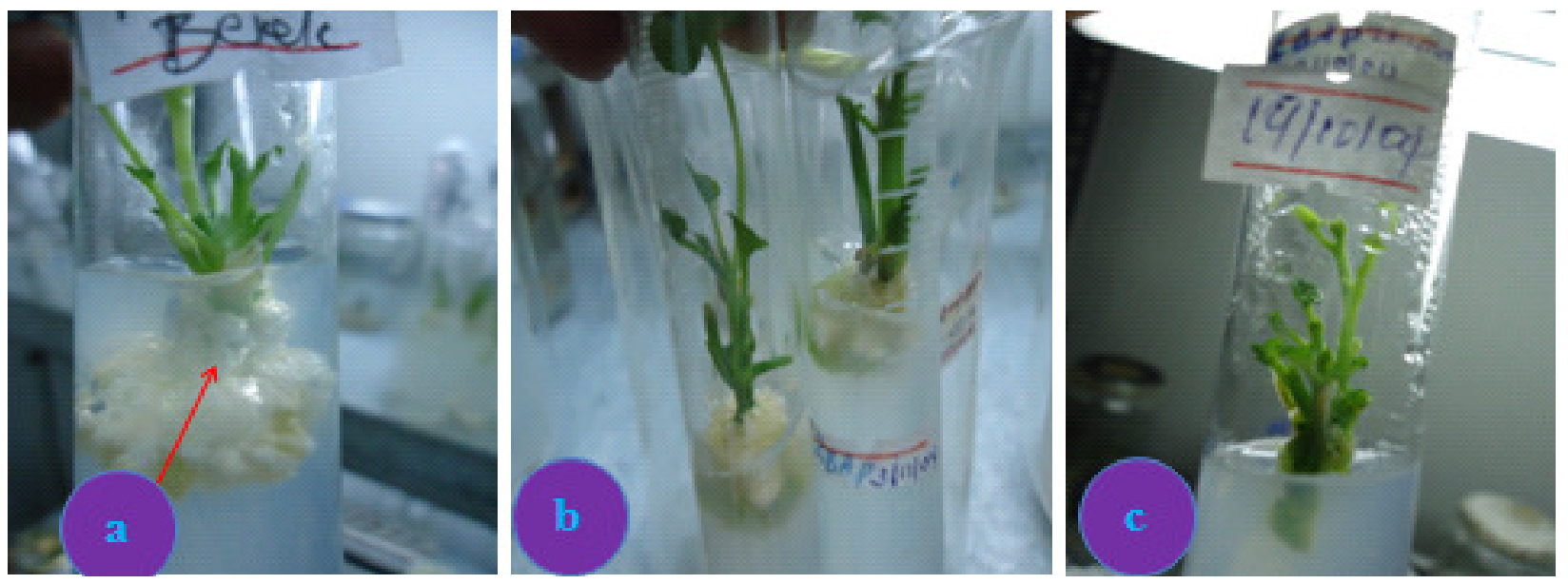

Figure 1. Effect of BAP on shoot induction. A) Unnecessary callus formation at the base of explants. B) Shoot induction on 2.0 $\mu \mathrm{M}$ of BAP. C) Shoot induced on $3.0 \mu \mathrm{M}$ BAP.

with $3 \% \mathrm{NaOCl}$ for 5 min followed by $74 \%$ shoot tip culture free of contamination treated with $\mathrm{NaOCl}(2 \% \mathrm{v} / \mathrm{v})$ for 5 min (Table 2).

\section{Effect of BAP and Kinetin on shoot induction}

Table 3 shows that the highest percentage $(82.38 \pm 0.48 \%)$ shoots were induced from nodal explants at BAP concentration of $3.0 \mu \mathrm{M}$ followed by $77.13 \pm 0.85 \%$ on a medium supplemented with $2.0 \mu \mathrm{M}$ of BAP. In the case of shoot tip explants, high percentages $(76.38 \pm 0.48 \%)$ of shoots were induced at $2 \mu \mathrm{M}$ BAP alone followed by $68.08 \pm 0.30 \%$ at $3.0 \mu \mathrm{M}$ of BAP. In growth regulators combination, high percent of induction were observed at $3.0 \mu \mathrm{M}$ BAP and $1.0 \mu \mathrm{M}$ kinetin; $62.68 \pm 0.58$ and $51.68 \pm 0.54 \%$ for nodal and shoot tip explants respectively. From the given concentrations, high concentrations of BAP and kinetin and a medium without BAP and kinetin resulted in low percentage of shoots induction. Thus, the lowest percentage shoot induction was observed on $5.0 \mu \mathrm{M}$ of BAP and 3.0 $\mu \mathrm{M}$ of kinetin for nodal and shoots tip; $23.68 \pm 0.54 \%$ and $20.95 \pm 0.421 \%$ respectively. BAP proved a more effective cytokinin than kinetin for multiple shoot induction (Table 3 and Figure 1).

\section{Effect of BAP and IAA on shoot multiplication}

High multiplication rate was obtained at the combination of BAP $(3.0 \mu \mathrm{M})$ and IAA $(0.5 \mu \mathrm{M})$ for nodal $(11.63 \pm 0.48)$ and shoot tip $(10.38 \pm 0.13)$ explants followed by $5.0 \mu \mathrm{M}$ of BAP and $0.5 \mu \mathrm{M}$ IAA $(9.60 \pm 0.45$ and $8.300 \pm 0.24 \%$, respectively). The longest shoot lengths were observed on the medium containing $5.0 \mu \mathrm{M}$ BAP with $1.5 \mu \mathrm{M}$ IAA for both explants. A medium without growth regulators (BAP and IAA) and a medium with high concentration of BAP and IAA alone and combination of the two resulted in low multiplication rate. This was for both explants at different concentration and with different shoot number per explants. 
Table 2. Interaction effect of sodium hypochlorite concentrations and its time of exposure on sterilization of explants.

\begin{tabular}{|c|c|c|c|c|c|c|c|c|c|}
\hline \multirow[b]{2}{*}{$\begin{array}{c}\text { Concentration } \\
\text { of } \mathrm{NaOCl}\end{array}$} & \multirow[b]{2}{*}{$\begin{array}{l}\text { Duration } \\
\text { (min) }\end{array}$} & \multicolumn{2}{|c|}{$\%$ Survived tissue } & \multicolumn{2}{|c|}{$\%$ contamination free explant } & \multicolumn{2}{|c|}{$\%$ Tissue death } & \multicolumn{2}{|c|}{$\begin{array}{c}\text { Survived tissue with } \\
\text { contamination }\end{array}$} \\
\hline & & $\begin{array}{c}\text { Nodal } \\
\text { (Mean } \pm \text { Std } \\
\text { Dev) }\end{array}$ & $\begin{array}{c}\text { Shoot tip } \\
\text { (Mean } \pm \text { Std } \\
\text { Dev) }\end{array}$ & $\begin{array}{c}\text { Nodal } \\
\text { (Mean } \pm \text { Std } \\
\text { Dev) }\end{array}$ & $\begin{array}{c}\text { Shoot tip } \\
\text { (Mean } \pm \text { Std } \\
\text { Dev) }\end{array}$ & $\begin{array}{c}\text { Nodal } \\
\text { (Mean } \pm \text { Std } \\
\text { Dev) }\end{array}$ & $\begin{array}{c}\text { Shot tip } \\
\text { (Mean } \pm \text { Std } \\
\text { Dev) }\end{array}$ & $\begin{array}{c}\text { Nodal } \\
\text { (Mean } \pm \text { Std } \\
\text { Dev) }\end{array}$ & $\begin{array}{c}\text { Shoot tip } \\
\text { (Mean } \pm \text { Std } \\
\text { Dev) }\end{array}$ \\
\hline 1 & 5 & $100.00 \pm 0.00^{a}$ & $100.0 \pm 0.00^{a}$ & $0.00 \pm 0.00^{k}$ & $0.00 \pm 0.00^{j}$ & $0.00 \pm 0.00^{\mathrm{j}}$ & $0.00 \pm 0.00^{k}$ & $100.0 \pm 0.00^{a}$ & $100.0 \pm 0.00^{a}$ \\
\hline 1 & 10 & $89.50 \pm 0.50^{d}$ & $86.33 \pm 0.58^{d}$ & $10.60 \pm 0.53^{i}$ & $13.57 \pm 0.51^{h}$ & $10.50 \pm 0.50^{h}$ & $13.67 \pm 0.58^{h}$ & $79.23 \pm 0.68^{c}$ & $72.77 \pm 0.68^{c}$ \\
\hline 1 & 15 & $80.50 \pm 0.50^{\mathrm{e}}$ & $71.67 \pm 0.42^{\mathrm{e}}$ & $21.00 \pm 1.00^{\mathrm{h}}$ & $21.67 \pm 0.58^{\mathrm{g}}$ & $19.50 \pm 0.50^{\mathrm{g}}$ & $28.33 \pm 0.42^{g}$ & $59.50 \pm 0.50^{d}$ & $50.00 \pm 0.80^{d}$ \\
\hline 1.5 & 5 & $95.00 \pm 1.00^{b}$ & $97.00 \pm 1.00^{b}$ & $4.33 \pm 0.58^{j}$ & $2.07 \pm 0.12^{i}$ & $5.00 \pm 1.00^{i}$ & $3.00 \pm 1.00^{j}$ & $90.67 \pm 1.15^{b}$ & $95.13 \pm 0.81^{b}$ \\
\hline 1.5 & 10 & $70.80 \pm 0.72^{f}$ & $66.17 \pm 0.29^{f}$ & $41.50 \pm 0.50^{\mathrm{e}}$ & $39.47 \pm 0.50^{\mathrm{e}}$ & $29.20 \pm 0.72^{f}$ & $33.83 \pm 0.29^{f}$ & $29.30 \pm 1.21^{\mathrm{e}}$ & $26.70 \pm 0.61^{e}$ \\
\hline 1.5 & 15 & $67.07 \pm 0.30^{f}$ & $61.13 \pm 0.81^{g}$ & $57.40 \pm 0.53^{b}$ & $52.83 \pm 0.29^{b}$ & $32.93 \pm 0.31^{\mathrm{e}}$ & $38.87 \pm 0.81^{\mathrm{e}}$ & $9.67 \pm 0.31^{\mathrm{h}}$ & $8.30 \pm 0.82^{h}$ \\
\hline 2 & 5 & $91.10 \pm 1.15^{\mathrm{c}}$ & $93.47 \pm 0.50^{c}$ & $79.43 \pm 0.60^{a}$ & $74.33 \pm 0.58^{a}$ & $8.57 \pm 0.62^{i}$ & $6.53 \pm 0.50^{i}$ & $11.67 \pm 0.58^{g}$ & $19.13 \pm 0.81^{\dagger}$ \\
\hline 2 & 10 & $60.50 \pm 0.50^{\mathrm{g}}$ & $57.20 \pm 0.35^{\mathrm{h}}$ & $46.93 \pm 0.12^{d}$ & $45.80 \pm 0.72^{d}$ & $39.50 \pm 0.50^{d}$ & $42.80 \pm 0.35^{d}$ & $13.23 \pm 0.75^{f}$ & $11.40 \pm 0.72$ \\
\hline 2 & 15 & $44.57 \pm 0.51^{i}$ & $40.00 \pm 1.00^{j}$ & $31.26 \pm 0.46^{\dagger}$ & $27.73 \pm 0.70^{f}$ & $58.77 \pm 0.27^{b}$ & $60.00 \pm 1.00^{b}$ & $13.30 \pm 0.36^{f}$ & $12.26 \pm 0.31^{g}$ \\
\hline 3 & 5 & $65.27 \pm 0.64^{f}$ & $60.73 \pm 0.64^{g}$ & $51.13 \pm 0.80^{c}$ & $48.07 \pm 0.12^{c}$ & $34.73 \pm 0.64^{\mathrm{e}}$ & $39.27 \pm 0.64^{\mathrm{e}}$ & $14.13 \pm 0.23^{f}$ & $12.67 \pm 0.61^{g}$ \\
\hline 3 & 10 & $53.33 \pm 0.58^{\mathrm{h}}$ & $52.57 \pm 0.51^{i}$ & $47.13 \pm 0.80^{d}$ & $47.13 \pm 0.81^{c}$ & $46.67 \pm 0.58^{c}$ & $47.43 \pm 0.51^{c}$ & $6.20 \pm 1.31^{i}$ & $5.43 \pm 0.38^{i}$ \\
\hline 3 & 15 & $27.33 \pm 0.58^{j}$ & $22.93 \pm 0.90^{k}$ & $26.77 \pm 0.68^{g}$ & $22.60 \pm 0.52^{\mathrm{g}}$ & $72.67 \pm 0.58^{a}$ & $77.07 \pm 0.90^{a}$ & $0.57 \pm 0.51^{j}$ & $0.33 \pm 0.58^{j}$ \\
\hline CV & & 0.92 & 0.97 & 1.76 & 1.58 & 6.35 & 2.0 & 2.09 & 1.85 \\
\hline
\end{tabular}

Means with the same letters in a column are not significantly different from each other by Ryan - Einot - Gabriel - Welsch Multiple Range Test (REGWQ) at a=0.5 \%.

The longest average shoot length was obtained from $5.0 \mu \mathrm{M}$ of BAP and $1.5 \mu \mathrm{M}$ of IAA $(5.43 \pm 0.33$ $\mathrm{cm}$ from nodal and $5.88 \pm 0.30 \mathrm{~cm}$ from shoot tip explants) (Table 4 and Figure 2).

The shoot length that was obtained from nodal explant was slightly longer than the shoot height observed from shoot tip explants. Medium with high multiplication rate per explants gave slightly smaller average length of shoot when compared to a medium giving more number of shoot per explants.

\section{Effect of IAA, IBA and NAA on roo proliferation}

The highest rooting percentage $(91.33 \pm 0.54 \%)$ was obtained on half-strength MS medium supplemented with $0.5 \mu \mathrm{M}$ of IBA followed by $87.75 \pm$ $0.65 \%$ of rooting at $0.5 \mu \mathrm{M}$ of NAA the same medium with minimum callusing. Among the given concentrations, the root inducing auxin hormones with high concentration had less rooting percentages with greater diameter of callus induction.
Naphthalene acetic acid (NAA) at a concentration of $1.5 \mu \mathrm{M}$ resulted to less percentage of rooting $(42.68 \pm 0.54 \%)$ that was less than the root induced from all the rest at high and low concentration (Table 5).

The longest shoots $(4.63 \pm 0.21 \mathrm{~cm})$ were observed from a medium of 1.0 NAA followed by 1.0 $\mu \mathrm{M}$ of IAA $(4.55 \pm 0.26 \mathrm{~cm})$. Smallest shoot height where observed from $0.5 \mu \mathrm{M}$ of IAA $(2.00 \pm 0.00$ $\mathrm{cm})$ followed by $1.5 \mu \mathrm{M}$ of IAA $(2.00 \pm 0.23 \mathrm{~cm})$. Largest mean numbers of roots were counted 
Table 3. Effects of different concentrations of BAP and Kinetin alone and in combination on MS medium for culture initiation of Anchote shoot tip and nodal explants.

\begin{tabular}{cccc}
\hline \multirow{2}{*}{ Concentration of PGRs $(\mu \mathrm{M})$} & \multicolumn{2}{c}{ Explant } \\
\cline { 2 - 4 } & Kinetin & Modal & Shoot tip \\
\hline BAP & 0 & $26.13 \pm 0.85^{\mathrm{p}}$ & Mean \pm STD \\
\hline 0 & 1 & $23.68 \pm 0.54^{\mathrm{q}}$ & $20.95 \pm 0.52^{\mathrm{p}}$ \\
0 & 2 & $27.38 \pm 0.48^{\mathrm{q}}$ & $26.43 \pm 0.43^{\mathrm{n}}$ \\
0 & 3 & $44.38 \pm 0.48^{\mathrm{j}}$ & $41.00 \pm 0.75^{\mathrm{h}}$ \\
0 & 0 & $46.73 \pm 0.60^{\mathrm{i}}$ & $35.88 \pm 0.30^{\mathrm{j}}$ \\
1 & 1 & $37.68 \pm 0.54^{\mathrm{l}}$ & $27.38 \pm 0.48^{\mathrm{m}}$ \\
1 & 2 & $42.75 \pm 0.53^{\mathrm{k}}$ & $36.75 \pm 0.65^{\mathrm{j}}$ \\
1 & 3 & $48.38 \pm 0.48^{\mathrm{h}}$ & $40.13 \pm 0.30^{\mathrm{h}}$ \\
1 & 0 & $77.13 \pm 0.85^{\mathrm{b}}$ & $76.38 \pm 0.48^{\mathrm{a}}$ \\
2 & 1 & $57.35 \pm 0.47^{\mathrm{g}}$ & $45.75 \pm 0.29^{\mathrm{e}}$ \\
2 & 2 & $55.43 \pm 0.43^{\mathrm{f}}$ & $43.53 \pm 0.43^{\mathrm{f}}$ \\
2 & 3 & $47.80 \pm 0.36 \mathrm{~h}^{\mathrm{i}}$ & $38.43 \pm 0.43^{\mathrm{i}}$ \\
2 & 0 & $82.38 \pm 0.48^{\mathrm{a}}$ & $68.08 \pm 0.30^{\mathrm{b}}$ \\
3 & 1 & $62.68 \pm 0.53^{\mathrm{c}}$ & $51.68 \pm 0.54^{\mathrm{c}}$ \\
3 & 2 & $60.08 \pm 0.79^{\mathrm{d}}$ & $47.92 \pm 0.22^{\mathrm{d}}$ \\
3 & 3 & $54.23 \pm 0.26^{\mathrm{g}}$ & $34.48 \pm 0.41^{\mathrm{k}}$ \\
3 & 0 & $46.88 \pm 0.62^{\mathrm{i}}$ & $42.55 \pm 0.42^{\mathrm{g}}$ \\
5 & 1 & $37.13 \pm 0.86^{\mathrm{l}}$ & $28.60 \pm 0.49^{\mathrm{l}}$ \\
5 & 2 & $32.68 \pm 0.54^{\mathrm{m}}$ & $27.53 \pm 0.50^{\mathrm{m}}$ \\
5 & 3 & $29.38 \pm 0.48^{\mathrm{n}}$ & $24.95 \pm 0.42^{\mathrm{o}}$ \\
5 & & 1.24 & 1.16 \\
\hline
\end{tabular}

Means within a column followed by the same letters are not statically significant at $p<0.05$ by Ryan - Einot - Gabriel - Welsch Multiple Range Test (REGWQ).

(11.63 \pm 0.48 ) from $1.5 \mu \mathrm{M}$ of IAA followed by $9.58 \pm 0.43$ on $1.5 \mu \mathrm{M}$ NAA. Highest concentrations of auxins resulted in less number of root. Relatively, less number of roots were observed (Table 5) from NAA at $0.5 \mu \mathrm{M}(2.68 \pm 0.28)$.

Longest root height was observed from a medium with less number of roots. There was smaller number of roots on NAA and IBA at different concentrations that accounted for larger number of roots than IAA (Figure 3 ).

\section{Acclimatization}

In vitro plantlets planted on black polyethylene pot and transferred to a greenhouse condition grew actively during the acclimatization process and no stress symptoms were observed especially on a soil mix of 2:1:1 (loam soil, coffee husk and sand, respectively). After two and half months, plantlets grew to 15 to $20 \mathrm{~cm}$ in height. In total, $82 \%$ of potted C. abyssinica plantlets survived 4 months after acclimatization (Figure 4).

\section{DISCUSSION}

Microbial contamination is one of the most serious problems both in seed culture and in plant cell and tissue cultures. These contaminants may be introduced with germplasm/explants into the culture medium and affect the potential of plant regeneration. Disinfectants such as ethanol, sodium hypochlorite $(\mathrm{NaOCl})$ with few drops of Tween 20 hamper the growth rate of fungus and bacteria on the growth medium (Odutayo et al., 2007; Ryan, 2008; Abera, 2010).

Plant material collection and handling were done according to the method of Zerihun et al. (2009). The collected explants were gently washed with tap water and detergents, followed by antifungal ( $0.3 \%$ Mancozeb) before treating with four different concentrations of $\mathrm{NaOCl}$ used for seed sterilization (2, 3 and $5 \%)$ and explants (1, 1.5, 2.0 and $3 \%$ ). ANOVA revealed statistically high significant effect $(p<0.0001$ at $a=5 \%)$ among the interaction 
Table 4. Effect of different concentrations and combinations of BAP and IAA treatments on shoot regeneration of anchote (C. abyssinica).

\begin{tabular}{|c|c|c|c|c|c|}
\hline \multicolumn{2}{|c|}{ Levels of PGR } & \multicolumn{2}{|c|}{ NODAL } & \multicolumn{2}{|c|}{ SHOOT TIP } \\
\hline BAP & IAA & $\begin{array}{l}\text { Shoot number } \\
\text { Mean } \pm \text { Std Dev }\end{array}$ & $\begin{array}{c}\text { Shoot length } \\
\text { Mean } \pm \text { Std Dev }\end{array}$ & $\begin{array}{l}\text { Shoot number } \\
\text { Mean } \pm \text { Std Dev }\end{array}$ & $\begin{array}{c}\text { Shoot length } \\
\text { Mean } \pm \text { Std Dev }\end{array}$ \\
\hline 0 & 0 & $1.00 \pm 0.00^{\prime}$ & $1.55 \pm 0.17^{\mathrm{ij}}$ & $0.83 \pm 0.23^{\mathrm{jk}}$ & $1.10 \pm 0.12^{l}$ \\
\hline 0 & 0.5 & $1.35 \pm 0.24^{\mathrm{kl}}$ & $1.58 \pm 0.15^{\mathrm{ij}}$ & $1.00 \pm 0.00^{\mathrm{jk}}$ & $1.20 \pm 0.16^{\mathrm{kl}}$ \\
\hline 0 & 1.0 & $1.33 \pm 0.10^{\mathrm{jkl}}$ & $2.10 \pm 0.12^{g h}$ & $0.65 \pm 0.17^{\mathrm{k}}$ & $2.00 \pm 0.00^{\text {ghi }}$ \\
\hline 0 & 1.5 & $2.00 \pm 0.00^{\mathrm{ijk}}$ & $1.83 \pm 0.22^{\mathrm{hi}}$ & $1.20 \pm 0.16^{\mathrm{ij}}$ & $2.13 \pm 0.15^{\mathrm{gh}}$ \\
\hline 1 & 0 & $2.43 \pm 0.33^{i}$ & $1.58 \pm 0.15^{\mathrm{ij}}$ & $1.65 \pm 0.17^{i}$ & $1.58 \pm 0.60^{\mathrm{ijk}}$ \\
\hline 1 & 0.5 & $2.20 \pm 0.23^{\mathrm{ij}}$ & $2.00 \pm 0.00^{\mathrm{igh}}$ & $2.55 \pm 0.17^{g h}$ & $2.43 \pm 0.17^{\mathrm{fg}}$ \\
\hline 1 & 1.0 & $1.45 \pm 0.58^{\mathrm{jkl}}$ & $2.33 \pm 0.22^{9}$ & $1.30 \pm 0.08^{\mathrm{ij}}$ & $1.83 \pm 0.13^{h i j}$ \\
\hline 1 & 1.5 & $1.88 \pm 0.30^{\mathrm{ijk}}$ & $2.30 \pm 0.00^{g}$ & $1.00 \pm 0.00^{\mathrm{jk}}$ & $2.15 \pm 0.20^{g h}$ \\
\hline 2 & 0 & $4.18 \pm 0.24^{\mathrm{fg}}$ & $2.30 \pm 0.14^{\mathrm{g}}$ & $2.40 \pm 0.14^{h}$ & $1.88 \pm 0.10^{\text {hij }}$ \\
\hline 2 & 0.5 & $7.73 \pm 0.63^{d}$ & $3.35 \pm 0.24^{\mathrm{de}}$ & $6.18 \pm 0.23^{d}$ & $2.45 \pm 0.06^{f g}$ \\
\hline 2 & 1.0 & $3.58 \pm 0.15^{\mathrm{gh}}$ & $2.75 \pm 0.29^{f}$ & $3.15 \pm 0.19^{f}$ & $2.90 \pm 0.12^{\mathrm{e}}$ \\
\hline 2 & 1.5 & $2.30 \pm 0.22^{i}$ & $4.63 \pm 0.30^{b}$ & $2.28 \pm 0.22^{h}$ & $2.98 \pm 0.05^{\mathrm{de}}$ \\
\hline 3 & 0 & $4.38 \pm 0.48^{f}$ & $2.23 \pm 0.26^{g h}$ & $2.95 \pm 0.10^{\text {fg }}$ & $2.30 \pm 0.14^{g h}$ \\
\hline 3 & 0.5 & $11.88 \pm 0.63^{a}$ & $2.95 \pm 0.10^{\text {ef }}$ & $10.45 \pm 0.53^{a}$ & $2.05 \pm 0.10^{g h}$ \\
\hline 3 & 1.0 & $8.00 \pm 0.41^{\mathrm{cd}}$ & $3.70 \pm 0.14^{\mathrm{cd}}$ & $7.23 \pm 0.21^{c}$ & $3.35 \pm 0.13^{\mathrm{cd}}$ \\
\hline 3 & 1.5 & $6.25 \pm 0.29^{e}$ & $5.70 \pm 0.24^{\mathrm{a}}$ & $4.25 \pm 0.29^{\mathrm{e}}$ & $2.80 \pm 0.22^{\text {ef }}$ \\
\hline 5 & 0 & $1.68 \pm 0.21^{\mathrm{ijkl}}$ & $1.35 \pm 0.19^{j}$ & $2.23 \pm 0.17^{h}$ & $1.50 \pm 0.08^{\mathrm{jkl}}$ \\
\hline 5 & 0.5 & $9.60 \pm 0.45^{b}$ & $4.00 \pm 0.16^{c}$ & $8.300 \pm 0.24^{b}$ & $3.70 \pm 0.12^{c}$ \\
\hline 5 & 1.0 & $8.53 \pm 0.19^{c}$ & $3.00 \pm 0.00^{\text {ef }}$ & $4.10 \pm 0.20^{\mathrm{e}}$ & $5.25 \pm 0.29^{b}$ \\
\hline 5 & 1.5 & $3.23 \pm 0.26^{h}$ & $5.43 \pm 0.33^{a}$ & $4.25 \pm 0.29^{e}$ & $5.88 \pm 0.30^{a}$ \\
\hline \multicolumn{2}{|c|}{$\mathrm{CV}$} & 7.59 & 6.91 & 6.47 & 7.81 \\
\hline
\end{tabular}

Means within a column followed by the same letters are not statically significant at $p<0.5$ by Ryan - Einot Gabriel - Welsch Multiple Range Test (REGWQ), Std Dev, standard deviation.

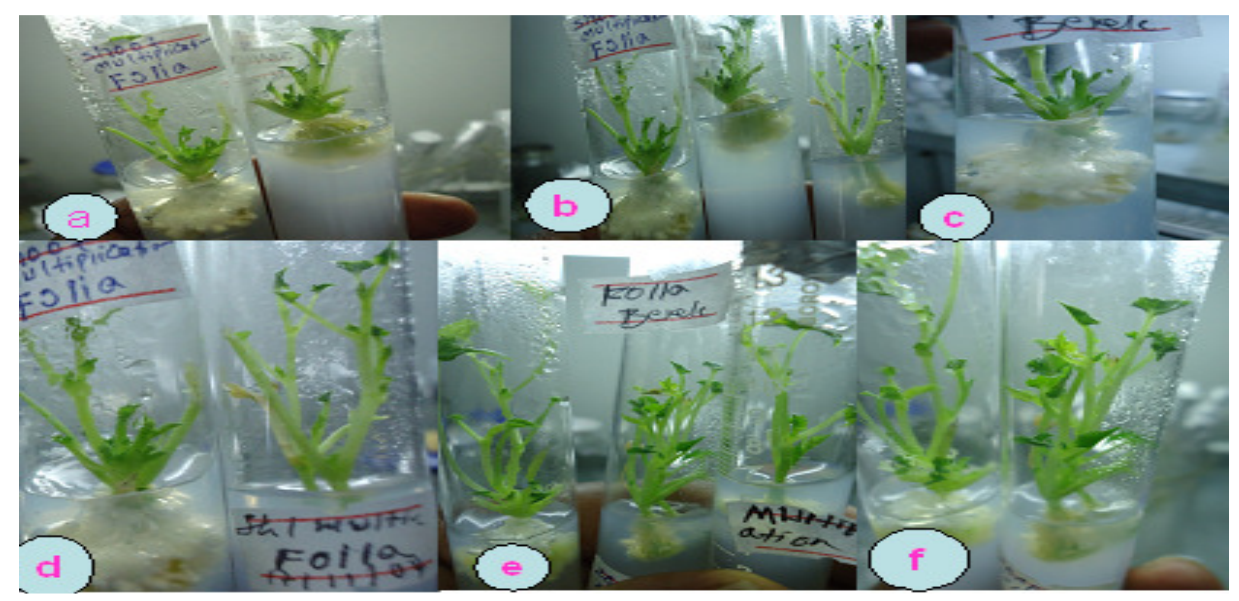

Figure 2. In vitro shoot multiplication of anchote. a, b and c, Shoots regenerated on $3.0 \mu \mathrm{M}$ of BAP and $0.5 \mu \mathrm{M}$ IAA. d, e, and $\mathbf{f}$, Shoots regenerated on $5.0 \mu \mathrm{M}$ of BAP and $1.5 \mu \mathrm{M}$ IAA with longest shoot. 
Table 5. Effect of various concentrations of IAA, IBA and NAA on rooting of proliferated shoots of $C$. abyssinica.

\begin{tabular}{|c|c|c|c|c|c|c|}
\hline \multicolumn{3}{|c|}{ Concentration of PGRs $(\mu \mathrm{M})$} & \multirow{2}{*}{$\begin{array}{l}\text { Rooting Percent } \\
\text { (Mean } \pm \text { SD) }\end{array}$} & \multirow{2}{*}{$\begin{array}{l}\text { Shoot height }(\mathrm{cm}) \\
\quad(\text { Mean } \pm \text { SD) }\end{array}$} & \multirow{2}{*}{$\begin{array}{c}\text { Root number } \\
\text { (Mean } \pm \text { SD) }\end{array}$} & \multirow{2}{*}{$\begin{array}{l}\text { Root length }(\mathrm{cm}) \\
\quad(\text { Mean } \pm \text { SD) }\end{array}$} \\
\hline IBA & IAA & NAA & & & & \\
\hline 0 & 0 & 0 & $0.00 \pm 0.00^{j}$ & $1.40 \pm 0.14^{\mathrm{e}}$ & $0.00 \pm 0.00^{9}$ & $0.00 \pm 0.00^{g}$ \\
\hline 0 & 0 & 0.5 & $87.75 \pm 0.65^{b}$ & $2.53 \pm 0.19^{c}$ & $2.68 \pm 0.28^{\dagger}$ & $1.48 \pm 0.05^{\dagger}$ \\
\hline 0 & 0 & 1 & $52.10 \pm 0.84^{i}$ & $4.63 \pm 0.21^{a}$ & $4.63 \pm 0.35^{\mathrm{e}}$ & $2.43 \pm 0.05^{d}$ \\
\hline 0 & 0 & 1.5 & $42.68 \pm 0.54^{e}$ & $3.18 \pm 0.24^{b}$ & $7.83 \pm 0.24^{c}$ & $3.28 \pm 0.22^{c}$ \\
\hline 0 & 0.5 & 0 & $84.95 \pm 0.74^{c}$ & $2.00 \pm 0.00^{d}$ & $2.95 \pm 0.10^{\dagger}$ & $2.40 \pm 0.14^{d}$ \\
\hline 0 & 1 & 0 & $64.63 \pm 0.48^{\dagger}$ & $4.55 \pm 0.26^{\mathrm{a}}$ & $6.48 \pm 0.41^{d}$ & $3.40 \pm 0.14^{\mathrm{c}}$ \\
\hline 0 & 1.5 & 0 & $54.68 \pm 0.54^{\mathrm{h}}$ & $2.00 \pm 0.23^{\mathrm{d}}$ & $11.63 \pm 0.48^{a}$ & $4.48 \pm 0.25^{b}$ \\
\hline 0.5 & 0 & 0 & $91.33 \pm 0.54^{\mathrm{a}}$ & $2.68 \pm 0.15^{c}$ & $3.25 \pm 0.29^{\dagger}$ & $2.05 \pm 0.10^{\mathrm{e}}$ \\
\hline 1 & 0 & 0 & $58.20 \pm 0.57^{9}$ & $2.70 \pm 0.24^{c}$ & $6.00 \pm 0.41^{d}$ & $1.75 \pm 0.17^{\dagger}$ \\
\hline 1.5 & 0 & 0 & $73.33 \pm 0.54^{d}$ & $3.25 \pm 0.29^{b}$ & $9.58 \pm 0.43^{b}$ & $5.63 \pm 0.21^{a}$ \\
\hline Mean & & & 63.5 & 2.89 & 5.50 & 2.69 \\
\hline CV & & & 0.92 & 7.29 & 6.03 & 5.75 \\
\hline$R$-square & & & 0.99 & 0.96 & 0.99 & 0.99 \\
\hline
\end{tabular}

Percentage increases/decrease in shoot height, root number and root height per explants is given by plus or minus ( \pm ). Means within a column followed by the same letters are not statically significant at $\mathbf{a}=\mathbf{5} \%$ by Ryan - Einot - Gabriel - Welsch Multiple Range Test (REGWQ).
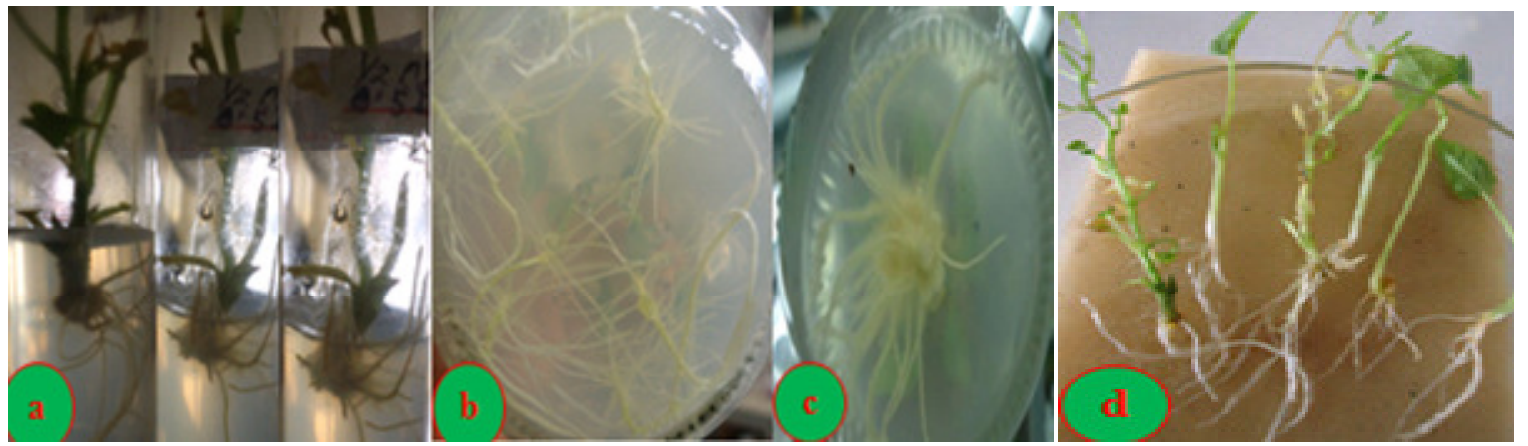

Figure 3. Root induced on different auxins. (a) Rooting on half - strength medium with $0.5 \mu \mathrm{M}$ IBA; (b) Rooting on half strength medium with $0.5 \mu \mathrm{M}$ NAA. (c) Rooting on half - strength medium with $0.5 \mu \mathrm{M} I \mathrm{AA}$. (d) Plantlets ready to transfer on sterile soil mix.

of sodium hypochlorite concentrations and time of exposures (time* $\mathrm{NaOCl}$ ). This show that long and short time exposure matter for the contamination free and survival percentage of the explants. Observation of higher contamination rate of explants in treatment combinations having lower concentration of sodium hypochlorite and short time of exposure might be due to insufficient concentration and time of treatment to kill the contaminating microbes. The higher the concentration of sodium hypochlorite with longer time of exposure, the better the removal of microbial contaminants, which was obtained as a synergistic effect of chlorine concentration and duration of time of treatment. The active ingredient of the chlorine, which is a powerful oxidant in high concentrations, can kill bacteria, fungi, etc, inhibiting bacterial cell wall synthesis, blocking bacterial DNA replication, bacterial protein synthesis and altering their shape and the physiological activities of their enzymes (Reed and Tanprasert, 1995; Hartmann et al., 2002). But this high concentration yield fewer percentages of plantlets. This might be due to inability of the plant tissue to survive with high concentration of sterilants, causing plant tissue death (Ervin and Wetzel, 2002). This plant tissue death was highly observed in shoot tip explant. The immaturity of the soft tissues of the shoot tip might cause inability to resist high concentration of sterilants than nodal explants (Hartmann et al., 


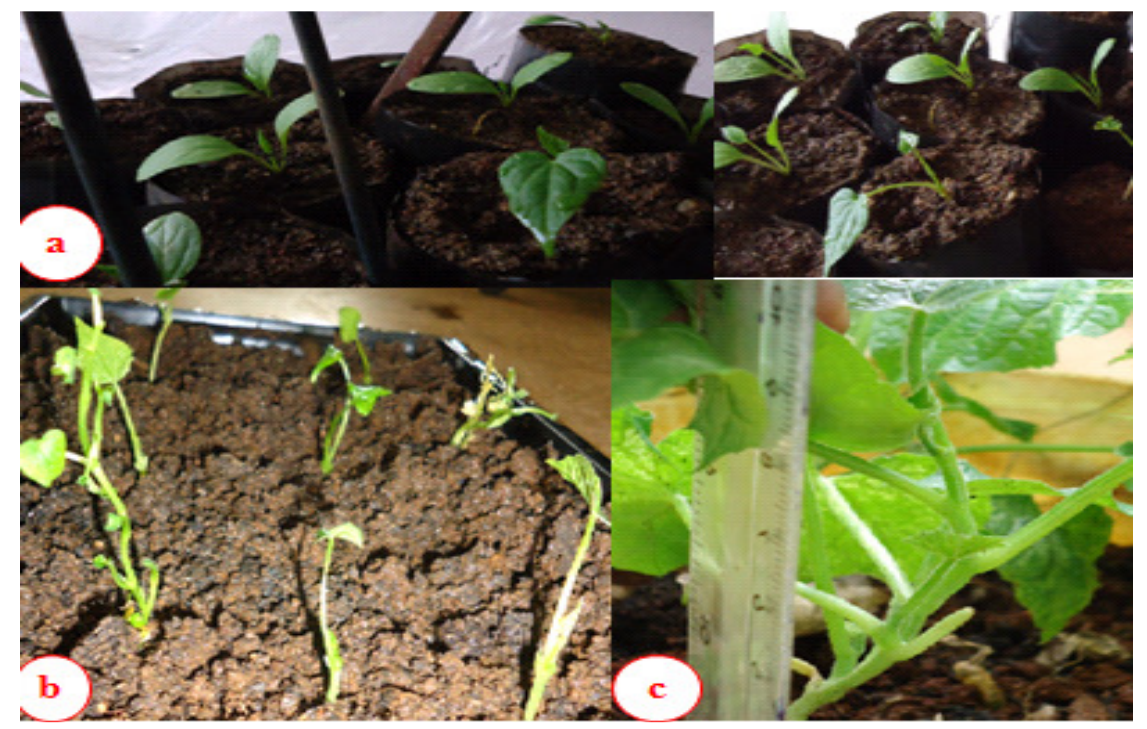

Figure 4. Acclimatization on 2:1:1 loam soil, coffee husk and sand. (a) Plantlets on black polystyrene plastic tube. (b) Plantlets on black polyethylene tray. (c) Four weeks old seedling of anchote.

2002).

ANOVA revealed a very high significant effect of MS strength and coated/decoatedness of seeds on germination efficiency. Decoated seeds showed high rate of germination than coated seeds. The presence of seed coat prevents the exchange of gases and water that induce germination (Hartman et al., 2002).

Growth and morphogenesis in vitro are regulated by the interaction and balance between the growth regulators supplied within a medium and the growth substances induced endogenously (Hartmann et al., 2002). Six benzyl amino purine is a best cytokinin growth hormone used for shoot induction in plant tissue culture (Singh and Singh, 2007; Sugla et al., 2007) and the same is true for C. abyssinica tissue culture. In the present study, among all the combinations and concentrations, the longest shoots $(6.1 \pm 0.85 \mathrm{~cm})$ and the highest percentage of shoot formation $(90.45 \%)$ were observed in treatment with $3.0 \mathrm{mg} / \mathrm{l} \mathrm{BAP}$ after 30 days of culture. However, the highest number of shoots per shoot tip $(16.5 \pm 0.95)$ was noted in the media containing $2.0 \mathrm{mg} / \mathrm{l} \mathrm{BA}$. Further increase in the concentration of BAP did not improve the shoot size and number. Several workers reported similar results in cucumber (Kathal et al., 1988; Misra and Bhatnagar, 1995) and in Cucurbita interspecific hybrid cultivar "Shintoza" (Sarowar et al., 2003). Increased concentration of BAP reduced shoot length and promoted massive base callus. Khan et al. (1983) obtained similar results at $2.0 \mathrm{mg} / \mathrm{l} \mathrm{BA}$ for Phoenix dactylifera L.). The present study also used $\operatorname{BAP}(1,2,3$ and $5 \mu \mathrm{M})$ and obtained $82 \%$ from nodal at $3.0 \mu \mathrm{M}$ and $68 \%$ from shoot tip explants induced at $2.0 \mu \mathrm{M}$ followed by $2 \mu \mathrm{M}$ and 3 of BAP, where 64 and $51 \%$ were obtained from nodal and shoot tip explants, respectively. High concentration of BAP induced lesser percent $(47 \%)$ of shoot and resulted to stunt shoot growth. The present study shows that $3 \mu \mathrm{M}$ BAP induced an average of 4.5 shoot from shoot tip explants and 6 shoot from nodal explants. The significance effect of BAP concentration with interaction of explants might be due to the concentration effect of BAP. Once both explants pass the sterilization stages, there was no significant effect between the explants in shoot induction.

In a significant development, it was observed that multiple shoot buds originated from nodal and shoot tip explants, when MS was supplemented with different concentrations (1.0,2.0, 3.0 and $5.0 \mathrm{mg} / \mathrm{l})$ of BAP along with IAA $(0.5,1.05$ and $1.5 \mathrm{mg} / \mathrm{l})$. The nodal explants showed slight swelling prior to the emergence of shoot buds developing from the pre-existing material 15 days after inoculation. Initially, four to eight shoot buds per explant emerged 25 days after inoculation and gradually the number of shoot buds per explant increased up to 10 to 12 on MS fortified with $3.0 \mathrm{mg} / \mathrm{l} \mathrm{BAP}$ along with com- 
bination of $0.5 \mathrm{mg} / \mathrm{I}$ IAA. But a very low number of buds developed in the combination of $1.0-2.0 \mathrm{mg} / \mathrm{l} \mathrm{BAP}$ along with 1.0 and $1.5 \mathrm{mg} / \mathrm{IAA}$; similar results were observed with BAP at a concentration of $5.0 \mathrm{mg} / \mathrm{l}$. It can be concluded that $3.0 \mathrm{mg} / \mathrm{l} \mathrm{BAP}$ and $0.5 \mathrm{mg} / \mathrm{l}$ IAA are suitable phytohormones for shoot proliferation and shoot elongation from nodal and shoot tip explants of $C$. abyssinica. This is in accordance with the results as reported earlier (John et al., 2001; Kulkarni et al., 2002; Nishikoshta and Bansal, 2002; Yokoya and Handro, 2002). Similarly, esse both auxin and cytokinin combination for inducing shoot organogenesis has been reported in leaf culture of Cicer ariutum (Swamy et al., 2000); of the cytokinin used BAP proved most effective in inducing shoots; the same finding were recorded in Capsicum spp (Phillips and Hubstenberger, 1985).

The present study also reveals highly significant effect between treatments (BAP* $\left.{ }^{*} A A\right)$, between treatments and explants (treatment*explants) for shoot multiplication and elongation, whereas there was no significant effect among explants for shoot length. In the present investigation, a high frequency of multiple shoot induction was achieved in C. abyssinica through nodal and shoot tip explants with BAP $(3.0$ and $5.0 \mu \mathrm{M})$, with $1.0 \mu \mathrm{M}$ IAA and combination of both $(0.5 \mathrm{mg} / \mathrm{l})$. These results are also in agreement with the observation of Plader et al. (1998). Further, an increase or decrease of this hormone level showed a negative trend in multiple shoot formation

For any micropropagation protocol, successful rooting of micro shoots is a prerequisite to facilitate their establishment in soil. An addition of an auxin, mainly IAA, IBA and NAA to the medium or free growth hormone was essential to induce rooting in the regenerated shoots (Daffala et al., 2011). In this study, half - strength MS medium supplemented with IAA (0.5 1.0 and, $1.5 \mu \mathrm{M})$, IBA (0.5 1.0 and, $1.5 \mu \mathrm{M})$ and NAA (0.5 1.0 and, $1.5 \mu \mathrm{M})$ were evaluated and relatively $0.5 \mu \mathrm{M}$ for IAA, IBA and NAA respectively gave good rooting percentage. The concentrations beyond these led to a decrease in the number of roots and root length per rooted explant and rooting rate. The root elongation phase is very sensitive to auxin concentration, and it is inhibited by high concentration of auxin in the rooting medium. Daffala et al. (2011) reported that roots may require a less concentration of auxin to grow, but root growth is strongly inhibited by its higher level because at this level, auxin induces the production of ethylene, a root growth inhibitor.

In the present study, compact callus formation inhibiting the growing shoots and very small number and inadequate root length were observed at higher concentration of almost all the given auxins. This result is in agreement with the study of Demeke and Hughes (1990), who reported that increasing concentration of auxins resulted to greater production of callus with short, thick and small number of roots. They also reported the production of thin and long roots with minimum callus induction from low concentration of auxins. Their result also confirmed that IBA at low concentration gave $90 \%$ of root induction with minimum calli induction for the other varieties, whereas, $91 \%$ of root induction for $C$. abyssinica variety 29 . However, the present study resulted in high percentage $(91 \%)$ of root induction by IBA at $0.5 \mu \mathrm{M}$. The effectiveness of IBA in rooting has been reported in $\mathrm{M}$. dioica (Nabi et al., 2002; Thiruvengadam et al., 2006), Melothria maderaspatana (Baskaran et al., 2009), M. charantia (Thiruvengadam et al., 2010) and Citrullus colocynthis (Meena et al., 2010). In contrast, NAA and IBA have been used successfully for in vitro rooting of wild as well as cultivated Cucumis species (Compton et al., 2001; Selvaraj et al., 2002).

Anitha and Pullaiah (2002) in Decalepis hamiltonii and Latha et al. (1998) in Porteresia coarctata also demonstrated similar results. Analysis of variance for the present study revealed that there was highly significance effect among the concentrations of the given auxins for all experimental variables, namely, rooting percentages, root number, and root length. The increase or decrease in concentration of these hormones led to variability of root induction percentage. Induction percentage was less at high concentration; shoot elongation was longer at low concentration; number of roots, was high at optimum low concentration; and root length was also based on the auxins concentrations. The longest root was measured from free PGRs half-MS length medium. What worth mentioning and should not be passed without mentioning is that the rooting medium was also used as shoot elongation. So there is no need of developing another protocol for shoot elongation.

In vitro induced shoots are very delicate and prone to sudden environmental changes that may damage the plant unless it is gradually adapted to the new environment. Hence, rooting and acclimatization is required to enable shoots adapt to the natural environment. The essentiality of appropriate root development in vitro is for successful establishment of anchote shoots during acclimatization (Hartmann et al., 2002). For this case, green and vigorous plantlets with large number of roots and root length of greater than $2 \mathrm{~cm}$ were planted in transparent polyethylene plastic box. The best soil mix for anchote acclimatization was 2:1:1 (top soil, coffee husk and sand). The plantlets were planted on either polyethylene tube that was made to provide good aeration, whereby 
more percentages of plantlets survived and it was covered with black shed net. Due to unsuitability of the environment, for the first week, plantlets wilted and only $62 \%$ of plantlets survived from plastic tray. In a polyethylene plastic tube and on sterilized 2:1:1 (loam soil, coffee husk and sand) soil mixes, $82.2 \%$ of the plantlets survived. This is in agreement with the results of Nabi et al. (2002) who showed that the addition of habitat (top forest) soil during hardening could increase the survival chances in the field.

A reliable regeneration protocol has been established for $C$. abyssinica. This work provides a foundation for further efforts to generate genetically improved $C$. abyssinica and related cucurbitaceous species.

\section{ACKNOWLEDGEMENTS}

The authors acknowledge the Research and Publication Office (RPO) of Jimma University for the financial support.

\section{REFERENCES}

Abera B, Negash L, Kumlehn J, Feyissa T (2010). In vitro regeneration of Taverniera abyssinica A. Rich: A threatened medicinal plant. Ethiop. J. Edu. Anc. Sci. 6:59-71.

Anand JR (2004). In vitro multiple shoot regeneration from nodal explants of Zehneria scabra (L.f.) Sonder - An important medicinal climber. Plant Tiss. Cult. 14(2):101-106.

Anitha S, Pullaiah T (2002). Invitro propagation of Decalepis hamiltonii. J. Trop. Med. Plants 3:227-232.

Anonymus (2011). West Wollega Zone agriculture and rural development office. Annual Report, pp.22.

Anugulati J (1988). Tissue culture of Coccinia grandis. Cur. Sci. 57:1232-1235.

Baskaran $\mathrm{P}$, Velayutham $\mathrm{P}$, Jayabalan $\mathrm{N}$ (2009). In vitro regeneration of Melothria maderaspatana via indirect organogenesis. In Vitro Cell Dev. Biol. Plant 45:407-413.

Compton ME (2000). Interaction between explant size and cultivar affects shoot organogenic competence of watermelon cotyledons. HortSci. 35:749-750

Daffala HH, Abdellatef E, Elhadi EA, Khalafalla MM (2011). Effect of growth regulators on in vitro morphogenic response of Boscia senegalensis (Pers.) Lam. Poir. using mature zygotic embryos explants. Biotech. Res. Int. 10:1-8.

Dawit A, Estifanos H (1988). Plants as primary sources of drugs in traditional health practices of Ethiopia. In: Engels, J.M.M., Hawkes, J.G and Melaku Worede (eds), plant genetic resources of Ethiopia. Cambridge university press. Birmingham, Alabama.

Demeke T, Hughes HG, Lee CW (1992) .Propagation of Phytolacca dodecandra (endod) by stem cuttings and seed. Trop. Agric. 69:301303.

Ervin GN, Wetzel RG (2002). Effects of Sodium hypochlorite sterilization and dry cold storage on germination of Juncus effuse $\mathrm{L}$. Wetlands 22:191-195.

Fekadu H (2011). Nutritional and Anti-nutrition's of Anchote (Coccinia abyssinica) tubers: LAP LAMBERT Academic Publishing, Addis Ababa Ethiopia. p.124.
Hartmann HT, Kester DE, Davies FT, Geneve RL (2002). Cell and tissue culture propagation In: Plant Propagation, principles and practices, 7th ed. PHI Learning, New Delhi, India.

Hora A (1995). Anchote, an endemic tuber crop. Jimma College of agriculture. Jimma, Ethiopia.

John S, John Robinson J, Natarajan E, Arockiasamy DI (2001). Micropropagation of Hyptis suaveolens (L.) Poit. (Labiatae) through nodal culture. Adv. Plant Sci. 14:561-565.

Kathal R, Bhatnagar SP, Bhojwani SS (1988). Regeneration of plant of leaf explants of Cucumis melo L. cv. Pusa Sharbati. Plant Cell Rep. 7:449-451.

Khan MA, Khalil MS, Al-Kahtani MS (1983). In vitro culture of different tissue of date palm (Phoenix dactylifera L.) offshoot. First Symp, on Date Palm. K.F.U. Al-Hassa, Saudi Arabia, pp.152-157.

Kulkarni VM, Varghney LR, Bapat VA, Rao PS (2002). Somatic embryogenesis and plant regeneration in a seeded banana (Ensete superbum (Roxb.) Cheesman). Cur. Sci. 83:939-941.

Latha R, Ajith A, Srinivasa RC, Eganathan, P, Balakrishna P (1998). In vitro propagation of salt-tolerant wild rice relative, Porteresia coarctata Tateoa. J. Plant Growth Regul. 17:231-235.

Lee YK, Chung W, Ezura H (2003). Efficient plant regeneration via organogenesis in winter squas ( Cucurbita maxim Duch). Plant Sci. 16:41-418

Meena MC, Meena R, Patni V (2010). High frequency plant regeneration from shoot tip explants of Citrullus colocynthis (Linn.) Schrad. - An important medicinal herb. Afr. J. Biotech. 9:5037-5041.

Mengesha D, Belew D, Gebrasillasie W, Sori W (2012). Growth and yield performance of Anchote. Asian J. Plant Sci.11:172-181.

Misra AK, Bhatnagar SP (1995). Direct shoot regeneration from the leaf explant of cucumber (Cucumis sativus L.) Phytomorphol. 45:47-55.

Murashige T, Skoog F (1962). A revised medium for rapid growth and bioassay with obacco issue cultures. Physiologia. Plantrum. 15:473497.

Nabi SA, Rashid Al-Amin M, Rasul MG (2002). Organogenesis in teasle gourd (Momordica dioica Roxb.). Plant Tiss. Cult., 12:173-180.

Nishikoshta K, Bansal YK (2002). Shoot tip culture for micropropagation of medicinal plant Sarpagandha (Rauvolfia serpentina Benth.). Exkurz, J. Phytol. Res. 15:95-99.

Odutayo OI, Amusa NA, Okutade OO, Ogunsanwo YR (2007). Sources of microbial contamination in tissue culture laboratories in southwestern Nigeria. Afr. Agri. Res. 2:067-072.

Phillips GC, Hubstenberger JF (1985). Organogenesis in pepper tissue culture. Plant cell Tissue. Org. Cult. 4:262-269.

Plader W, Burza W, Rusinowski Z (1998). The relationship between the regeneration system and genetic variability in cucumber (Cucumis sativus L.). Euphytica 103:9-15.

Reed BM, Tanprasert P (1995). Detection and control of bacterial contaminants of plant tissue cultures: A review of recent literatures. Plant Tiss. Cult. Biotechnol. 1:37 - 43.

Rakhi C, Rekha HR, Kumar MV (2010). Assesement of regenerative potentiality of cotyledon explants of some indigenous varieties of Cucurbits using varied concentrations of Cytokinins. In: Role of Biotechnology in Food Security and Climate Change. Islam AS, Haque MM, Sarker RH and Hoque MI (Eds). Proc. Sixth Intl. Plant Tissue Cult. \& Biotech. Conf., December 3-5, 2010, Bangladesh Assoc. Plant Tiss. Cult. Biotech. pp.27- 40.

Ryan J (2008). Understanding and managing cell culture contamination, Technical Bulletin, 900 Chelmsford St. Lewell, MA.

Sarowar S, Oh HY, Hyung NI, Min BW, Harn CH, Yang SK, Ok SH, Shin JS (2003). In vitro micropropagation of a Cucurbita interspecific hybrid cultivar-a root stock plant. Plant Cell Tiss. Org. Cult. 75:179182.

Selvaraj N, Vengadesan G, Vasudevan A, Prem Anand R, Ramesh Anbazhagan V, Ganapathi A (2002). Micropropagation of Cucumis 
sativus L. from field grown plants. In: Maynard DN (Ed.), Proceedings of the Cucurbitaceae, ISHS Press, Belgium, pp. 149-156.

Singh BS, Singh MP (2007). Findamental of plant biotechnology. Satish serial puplication house, New Delhi, India.

Sugla T, Purkayastha J, Singh SK, Solleti SK, Sahoo L (2007). Micropropagation of Pongamia pinnata through enhanced axillary branching. In vitro Cell Dev. Biol. Plant. 43:409 - 414.

Tarek AS, Soliman AO, Yousry AB (2008). In vitro propogation of two triploid hybrids of watermelon through adventitious shoot organogenesis and shoot tip culture Acta Biologica Szegediensis. 5(1):27-31.

Thiruvengadam M, Rekha KT, Jayabalan N (2006). An efficient in vitro propagation of Momordica dioica Roxb. ex. Willd. Philipp. Agric. Sci. $89: 165-171$
Thiruvengadam M, Rekha KT, Jayabalan N, Yang $\mathrm{CH}$, Chung IM (2010). High frequency shoot regeneration from leaf explants through organogenesis of bitter melon (Momordica charantia L.) Plant Biotechnol. Rep. 4:321-328.

Yokoya NS, Handro W (2002). Effect of plant growth regulators and culture medium on morphogenesis of Solieria filiformis (Rhodophyta) cultured in vitro. J. Appl. Phycol. 14:97-102.

Zerihun A, Ayelign M, Alemayehu T, Wondyfraw T (2009). Efficient in vitro multiplication protocol for Vanilla planifolia using nodal explants in Ethiopia. Afr. J. Biotech. 8:6817-6821. 